Polak, J. (2019). Determining Probabilities for a Commercial Risk Model of Czech Exports to China with Respect to Cultural Differences and in Financial Management. Journal of Competitiveness, 11(3), 109127. https://doi.org/10.7441/joc.2019.03.07

\title{
DETERMINING PROBABILITIES FOR A COMMERCIAL RISK MODEL OF CZECH EXPORTS TO CHINA WITH RESPECT TO CULTURAL DIFFERENCES AND IN FINANCIAL MANAGEMENT
}

- Josef Polak

\begin{abstract}
Certain risks associated with particular human activities cannot be eliminated, with commercial risks representing factors of business success or failure. In the current turbulent environment, proper risk assessment and management is of utmost importance in maintaining competitiveness. The aim of this paper is to present the output of our research which focused on the assessment of commercial risk faced by exporters to China, specifically, determining the probabilities for commercial risk model management. Along with this, the cultural context of the Chinese market influencing risk size are explored, particularly the concepts of tan-wej, kuan-si, li-t'ie and mien-c', the effect of which was confirmed by our exporter survey. The research focused on Czech companies exporting goods and technologies to China. The study involves manufacturing enterprises (section C, CZ-NACE Rev. 2) as well as, more specifically, medium and large scale engineering, along with chemical and electrical power companies. Firms exporting common consumer goods, raw materials and recyclables were excluded from the study. The data were obtained from controlled interviews with company representatives (with 58 percent of the exporters participating in a 2013 research) and from Justice.cz (2016) which published economic results of all exporters registered in 2015. The study outcomes were further reviewed in 2016-2017 using follow-up interviews and literature reviews. In collecting the primary data and verifying research outcomes, semi-structured and structured interviews were conducted, following which methods of descriptive statistics and statistical dependence analysis were applied. The findings allow for the construction of a commercial risk assessment model for export to China, involving relative risk costs.
\end{abstract}

Keywords: commercial risk, competitiveness, corporate finance, cultural differences, modelling, risk assessment JEL Classification: F14, G32

Received: March, 2019

1st Revision: July, 2019

Accepted: July, 2019 


\section{INTRODUCTION}

The Czech economy has traditionally been export-oriented, affected by the German market in particular. It is generally acknowledged that the Czech Republic benefits from the open EU market, as evidenced by data from the Czech Statistical Office (CSO, 2017). At the same time, the statistical data indicate a significant excess of imports over exports to China, the latter making up just over one percent of total Czech exports. Other economies also report a passive balance of foreign trade with China (Statistics Explained: International trade in goods, 2018). The assessment of individual countries' export performance to China, however, is not the subject of this research; its primary focus is on the commercial risk faced by all foreign business entities operating in the Chinese market, thus making the study outcomes significant for all countries involved.

The Chinese market is attractive in terms of its volume and potential. It is, however, also shaped by the peculiarities of a local culture significantly different from that of the Czech Republic. In spite of this, Czech exporters have long been successful in selling luxury and technologically advanced products to this distant market. They have understood the local market conditions and the threats posed by commercial risks (Polák, 2016), with their failures and successes being reflected on in a previous paper. Examining commercial risk thoroughly, the present research outcomes should prove quite useful and educational for business people who currently work in the Chinese market or who plan to expand there in the future.

The present study represents a follow-up outcome of an original research project based on a survey carried out with Czech export enterprises which partially covers the issue of commercial risk management when exporting to China. In contrast to more narrowly-focused papers, this article addresses broader risk aspects in a more comprehensive way. The study is based on the cultural and historical considerations which are reflected in the particularities of foreign trading in the indisputably rapidly developing Chinese market. Despite the massive potential customer base, however, an unprepared seller trying to penetrate the local market is likely to fail. This research project aspires to make an original, valuable contribution to the theory along with a practical impact on both enterprises expanding into the Chinese market and the wider professional public dealing with China in other ways. More specifically, the article aims at determining the probabilities for commercial risk model management. It is obvious from the results which areas of commercial risk should definitely be secured by exporters.

The theoretical background section which immediately follows deals generally with the Chinese economy and cultural differences which can affect the size of commercial risk. In the methodology subchapter, the research sample and selected risks are defined along with the methods of data processing and variable calculation, which allow for the construction of a commercial risk assessment model. Empirical results are discussed in the next section, covering both cultural analysis outcomes and "hard" mathematical data as well as assessing certain modes of risk exposure. Finally, the conclusions summarize the study outputs and their limitations, outlining the directions of further research. 


\section{THEORETICAL BACKGROUND}

China has long represented an extensive market that appears to be open and ready for investors looking for a place with potentially high demand. High market growth and demand itself, however, is not the key to success, a result which has been confirmed by many firms trying to enter the Chinese market without having taken local political conditions associated with the whims and fluctuations of communist party officials into account. This long-term, empirical finding is supported by various studies (Chen et al., 2018; Luo et al., 2017; Zhuang et al., 1998). To pursue market entry opportunities, companies have to negotiate on the spot, which can be rather costly. For Chinese business people (as well as ordinary citizens), the use of ICT and the internet in banking in particular has become commonplace, as is documented in the literature (Yao et al., 2018; Zheng, 2011).

\subsection{Economic and technological aspects of China as a partner}

Since online purchase options are available worldwide, the question of whether this phenomenon can also be used to enter the Chinese market for export is legitimate. Such problems are a common issue of risk assessment before commencing further business activities. The quality of the risk analysis depends on the executives' competence, with even large enterprises paying the price for underestimating risk management, which is crucial for successful completion of a business transaction. In terms of the present research, commercial risk is defined so that both theoretical interdisciplinary knowledge and practical requirements could be taken into consideration.

The Chinese economy boasts of an enormous market, with exports significantly exceeding imports. Considering mutual trade between the Czech Republic and China over the period 2010 2017, Czech exports make up only about one percent of all imports to China. Imports to the Czech Republic, on the other hand, reached 12.5\% in 2017 (CSO, 2017, 2018). Such striking differences along with the general growth potential of China and the need for the diversification of Czech exports represent other reasons for research focused on this market. Goals of expansion into this market are in line with the government Export Strategy of the Czech Republic 2012-2020, which ranks China among the "priority" export countries. The Czech economy includes diverse entities, ranging from large enterprises to middle-sized and small (family-run) firms, all of which have a significant impact on GDP growth and regional development. In order to reach their full potential, however, the new generations of entrepreneurs have to gain experience in doing business overseas (Mareš \& Petrů, 2018). The findings of both previous and current research encourage the growth of and access to a considerable business knowledge base, thus promoting entrepreneurial success and enhancing competitiveness.

China may seem like a strange world for Europeans, as represented by its distinct culture, demographic and social structure, legal system, religion, way of thinking, as well as spoken and written language (Wang, 2016). Wang also addresses relevant aspects of Chinese culture, the knowledge of which is crucial for both importers and exporters. Understanding the local culture as a prerequisite for launching a constructive dialogue between would-be trading partners is highlighted in Palát (2014). 
China is at the forefront of technological advancements which are determining the future direction of the world economy. The changes in the country are well-illustrated by the issue of green technologies, the long-term neglect of which China was once heavily criticized for. Currently, however, besides energy-saving technologies, those reducing the carbon footprint in particular have come to be fully embraced and utilized, as seen in relatively newly available sources (Halleck-Vega et al., 2018; Song et al., 2018; Xu et al., 2018). The banking sector in particular has responded by offering so-called "green loans" (Zheng, 2011). Nevertheless, the availability of energy resources looms as one of the major environmental challenges for the country. The strenuous efforts put forth by China into expansion within the energy sector are well documented in, e.g. Cabré eet al. (2018), including the employment of state-of-the-art technologies along with the negative impacts associated with the respective economic and societal dynamics.

The epithet "communist" seems to be fading away vis-à-vis China's booming society and economy. Following the recent Industry 4.0 trend of automation and data exchange in manufacturing, China no longer ranks among countries with a cheap labour force (Li, 2018). Arguably, only highly innovative and technologically advanced firms can survive. While maintaining its traditional culture and values, the new technologically-minded generation of entrepreneurs, manufacturers, buyers and sellers is changing the country's mind set (Zhang et al., 2018). The complexity and ambivalence of these developments also affect the commercial risk examined in the present study.

\subsection{Cultural factors affecting trade with China}

Some principles of Chinese society and culture which have currently come into debate are, for example: tan-wej, kuan-si, li-t'ie and mien-c'.

For characteristics of particular concepts, see below.

One of the fundamental differences between Chinese and Western societies is the relationship between individual and collective identities. While Western society places emphasis on personal development, welfare and independence, drawing clear distinctions between individuals, Chinese society essentially emphasizes significantly different values. By and large, the Chinese feel that they should accept the world around them as it is without trying to remake it. They should willingly submit to the authority exercised over them because their personality is not as important as their role in a group. From a historical point of view, the group is a wider family, a school class, a military unit, or a working team. Within the collective, the issues are discussed until a consensus is reached and subsequently accepted by the whole group regardless of alternative personal views. Hence, it is unlikely to get a Chinese person's opinion inconsistent with that expressed by the group. The Chinese thus adopt a certain agreement, expecting support and protection from the whole team in exchange for obedience and loyalty. Instead of prioritizing one's own interest, they must make decisions with respect to the entire group (Hofstede, 1997; Yeh \& Xu, 2010).

The concept of a group is closely associated with the work unit (tan-wej), particularly renowned in the times of Maoist communism. The influence of such work groups grew deeply in everybody's life. Chinese people did not choose their work units - having left school, they were as- 
signed to them. In order to change one's unit, they had to contact influential friends (kuan-si), or request a change using an advertisement. The work unit played a pivotal role not only in job placement and promotion, but also in marriage and other personal life events. Running the work-unit scheme, the government provided workers with the access to better health care and scarce commodities. Given the current need to significantly increase workforce mobility and streamline business management, work units have been steadily declining in importance (Bedford, 2011; Seligman, 2007).

Apart from the above-mentioned work-team orientation, Yeh \& Xu (2010) evaluate social effects of cultural legacy (Confucian in particular) kept as a treasure for everyday use. Positive impacts include the creation of harmony resulting from respect for traditions, hierarchy, authority and the interest of a wider collective and the elderly. The negative influence, on the other hand, is exercised by centralized decision-making which is too distant from local problems, not allowing to flexibly respond to ever-changing situations and minimize various risks. Overestimation of the hierarchy and the experience of the elderly as well as excessive conservatism represent other serious drawbacks carrying negative implications for decision-making practice and the adoption of consensual ideas and innovations. The Chinese are aware of these facts, recent development being stimulated by dramatic, positive changes that respect cultural traditions.

Similar factors are identified by Jia et al. (2012) in the Chinese network of connections (kuan-si) and in Russian personal relationship network (svyazi). Ip (2009) and Yeh \&Xu (2010) analyse impacts of personal ties upon Chinese society, highlighting the extension of their influence to business relations as well. Apart from positive ones, such as asset sharing, common problem solving and coping with uncertainty, the authors deal with negative aspects - e.g. excessive bureaucracy, clientelism, nepotism and corruption spreading through society. The ambivalent power of personal connections, based on a system of reciprocally provided services, thus penetrates deep into national and private organizations as well as ordinary citizens' lives, which seems inconceivable from the Western pragmatic perspective. Ineffectiveness of clientelism and ethical aspects of kuan-si are also analysed by Fan (2002) and Bedford (2011). The excessive use of kuan-si along with the concept of mien-c (see below) in big enterprises with a large organizational structure is addressed by Tam (2016) as a source of inefficiency and a brake of development, supporting the findings of Yeh \& Xu (2010). Gao et al. (2012), on the other hand, perceive kuan-si as a gateway that assists people and firms to break their path through the cumbersome Chinese bureaucracy and hierarchical structures, helping bridge cultural differences. According to Wang (2016), understanding these distinctions paves the way for international business trade dealings.

Developing an informal network of relationships and thorough preparation for difficult negotiations are not the only prerequisites for success. The Chinese are fond of the magic of subtle courtesy of behaviour (li-t'ie) emerging from a set of rules and customs. The guest is always welcomed, often with exaggerated care, the decline of an invitation to the table being usually ignored. Regardless of internal feelings, the host always holds a positive attitude and maintains the harmony shown, never causing embarrassment to the guest (Seligman, 2007; Tsai et al., 2011).

The concept of face (mien-c') is directly linked to the philosophy of interpersonal relationships in China and much of Asia. People have to behave according to the given virtues and principles. Having a "face" is essential for self-esteem and good reputation. It is not just about losing or 
keeping one's face. In the Chinese concept of the counterpart, the face can be given to the other person by flattering and paying compliments and respect. The other person's face, however, can be damaged by, for example, verbal assault or disapproval in public, a weak excuse for refusing an invitation to dinner, not showing respect, etc. The Chinese avoid saying "no" in a direct confrontation. The face can be lost due to inappropriate behaviour associated with an uncontrolled public demonstration of emotions such as anger, fear, joy, etc. The same reaction may be triggered by the revocation of an order or opinion, indicating a thoughtless or uninformed decision made. People usually get out of such situations using a fictional apologetic story. In this sense, the face is to be maintained by organizations and legal entities as well - ministries, businesses and individual entrepreneurs - for example, in the form of an unfair price discount, thus enabling the counterpart to earn the reputation (i.e. to get the face), or by tough negotiation for maximizing one's business results. The face can also be damaged at the government level by, for instance, undignified reception of a state visit (Seligman, 2007; Tam, 2016).

The above-mentioned factors have a major impact on commercial risk perception because they are directly linked to the essence of Chinese thinking and hence to the management of business transactions.

A crucial role in promoting international business and mediating between the actors in the kuansi network is assigned to national state authorities. Dobeš et al. (2017) analyse government growth policies of creating a favourable business environment through financial backing and reducing the costly administrative burden on entrepreneurs. For Czech export companies, a supportive business environment policy pursued by state foreign diplomacy may provide a distinct competitive advantage. Active engagement in business activities is an important goal of the diplomatic representation abroad, performing an intermediary role in introducing Czech firms to potential partners and settling possible disputes, or if there are major problems, suspending or blocking business dealings. It can be assumed that without a good knowledge of local conditions, partners and customers, legal regulations, language and, for example, without market research, it is very difficult to succeed in foreign markets (Petrů et al., 2019). Managing international commercial risks is thus not only about senior executives' skills and familiarity with cultural landscape of the foreign country, but it also depends on the effectiveness of government export assistance.

\subsection{Coping with risk}

Corporate management's ability to work with risk is the subject of research in many countries. Recent study conducted by Hudakova et al. (2018), for example, follows up on similar research carried out in the Czech Republic, Poland, Hungary and Serbia. A considerable number of risk management models generate a range of studies and manuals dealing with the issue; the following selection lists just a few examples - Alma (2017); Brillinger (2018); Dostál et al. (2005); Fotr \& Hnilica (2014); Korecký \& Trkovský (2011); Valaskova et al. (2018). A frequently discussed problem is the client's creditworthiness rating and the creation of the credit risk model (Alma, 2017). Financial risk assessment models use data on prosperity and profitability factors determined (Valaskova et al., 2018; Kliestik et al., 2018). Other current research programmes develop the advanced models that identify, analyse and evaluate risks in recurring processes (Brillinger, 2018). 
Commercial risk assessment relevant to this article is particularly addressed by financial market research studies focusing on rating, solvency and credit risk (Amat et al., 2017; Skoglund \& Chen, 2017; Belás et al., 2012) or on credit risk transfer in the supply chain (Jorge et al., 2017). An alternative view on client-related risk was presented by Bott \& Milkau (2018) describing "risk culture" from the perspective of people "interacting in dynamic and intertemporal commercial relations". In terms of the present paper, however, the major drawback of the above-mentioned and other secondary sources is too narrow focus on commercial risk manifestations. For the needs of export companies, it was therefore appropriate to adopt a modified approach outlined in this study.

The present commercial risk assessment model for trading with one of the most dynamic economies is unique in linking commercial risk occurrences with local business and cultural practices.

For the purpose of this paper, commercial risk was defined using an extensive literature on the issue (Černohlávková, 2007; Grath, 2008; Machková, 2010; Špaček, 2014), exploring the following manifestations of this complex phenomenon: business partner's withdrawal from the contract, contract parameter change brought about by one contracting party, unjustified refusal of the product by the customer, payment default of the customer, customer insolvency.

From the point of view of both domestic and foreign firms, the above negative forms of commercial risk can be generalized as a failure to complete a binding contract, its non-standard completion, or a default on or late contract payments.

Given large population and sample sizes, an appropriate statistical modelling technique for exploring conditional and unconditional probabilities was employed (see below).

\section{RESEARCH OBJECTIVE AND METHODOLOGY}

The aim of the paper is to present the output of the research focused on the assessment of commercial risk faced by exporters to China, specifically, determining the probabilities for a commercial risk model management. Along with that, outcomes of the content analysis of the local market's cultural traits affecting the risks are discussed.

The article presents the results of primary research conducted over the period 2012-2015 and their subsequent verification in 2016 and 2017. The research focused on Czech companies exporting goods and technologies to China. Information on commercial risk experience of a selected sample of business entities and economic results of all current Czech exporters were collected, excluding firms exporting common consumer goods, raw materials and recyclables. The study involves manufacturing enterprises (section C, CZ-NACE Rev. 2), more specifically, 40 medium and large engineering, chemical and electrical power companies operating in the year 2015. Table 1 below provides an overview of the number of enterprises operating in the industries concerned. It is to be noted that companies exporting from the Czech Republic to China, whose knowledge base entitles them to be included in the research, make up $4.5 \%$ of their total number. 
Tab. 1 - Manufacturing companies operating in the Czech Republic (2012-2016; research-relevant). Source: Amadeus database, 2018

\begin{tabular}{|l|l|l|l|l|l|}
\hline Year & 2012 & 2013 & 2014 & 2015 & 2016 \\
\hline $\begin{array}{l}\text { Number of medium } \\
\text { enterprises }\end{array}$ & 674 & 666 & 686 & 671 & 693 \\
\hline $\begin{array}{l}\text { Number of large enter- } \\
\text { prises }\end{array}$ & 189 & 194 & 194 & 209 & 202 \\
\hline Total number & 863 & 860 & 880 & 880 & 895 \\
\hline
\end{tabular}

The data were obtained from controlled interviews with companies' representatives (58 percent of exporters participating in the 2013 research) and from Justice.cz (2016) which published economic results of all exporters registered in 2015. The study outcomes were further reviewed in 2016-2017, using follow-up interviews and literature reviews.

A chosen starting point for constructing a commercial risk probability model of export to China is the nature of the random variable - the occurrence of the partial commercial risk. This is a discrete random variable with a binomial distribution of probability, i.e. the risk does or does not occur. Thus, it is possible to determine the so-called probability of success, which is precisely the probability of the risk situation. This random variable is defined as

$X \approx B i(n ; p)$,

where $\mathrm{n}$ is the number of experiments, i.e. the range of random selection, and $\mathrm{p}$ denotes the probability of success in one experiment (see Anděl, 2007).

The n number of experiments and p probability of success in one of the trials represent the parameters of the binomial distribution. Parameter $p$, i.e. the probability of commercial risk within a business contract, is of utmost importance. For small-scale samples, this parameter is relatively easy to derive as a ratio

$p_{0}=m / n$,

where $\mathrm{m}$ is the number of experiments in which the randomized phenomenon was observed (Anděl, 2007).

Since the basic data set is rather small, an additional test for statistical significance is needed to confirm the likelihood of the occurrence of the partial commercial business risk. The hypothesis that the proportion of $\mathrm{p} 0$ elements of the set possesses the studied property is based on empirical findings that this property is exhibited by $m$ statistical units from a randomized sample of $n$ units. The null hypothesis can thus be written as

$H_{0}: p=p_{0}$.

Unlike in other tests, an alternative hypothesis in three different versions can be proposed, its formulation determining the area of acceptance of the null hypothesis.

The test criterion $\mathrm{t}$ follows the normal distribution and has a form of (Hendl, 2015)

$t=\frac{m / n-p_{0}}{\sqrt{\frac{p_{0 \times\left(1-p_{0}\right)}}{n}}}$ 
Since there is only a small statistical set available, the hypothesis test of the p-binomial distribution parameter was not primarily used to verify the null hypothesis from the detected proportion, but to determine the maximum and minimum probability when the null hypothesis still applies. This means that alternative hypotheses in the form $\mathrm{p}>\mathrm{p} 0$ and $\mathrm{p}<\mathrm{p} 0$ to determine the minimum and maximum probabilities, respectively, were proposed. Finding these probabilities was then based on the solution of the equation with one unknown, namely $\mathrm{p} 0$, the test criterion t becoming 1.645 and -1.645 for the minimum and maximum probabilities at a significance level of $\alpha=0.05$, respectively. As mentioned before, these are the quantiles of the Gaussian normal distribution (Hendl, 2015).

A commercial risk model is based on basic research outcomes that reveal conditional and unconditional probabilities - the likelihood of partial risk being unconditional, that of additional costs conditional. Both primary and secondary research, the former undertaken in the form of structured interviews supplemented by questionnaires, creates the necessary database.

The choice of suitable methods was particularly affected by the nature and availability of research data. Common statistical methods, as well as those based on logical grounds, have been applied, their outputs forming the basis of modelling methodology.

There are six pairwise logically-grounded methods, namely induction/deduction, analysis/synthesis and abstraction/concretization. Out of the four fundamental techniques of qualitative research - i.e. direct observation, interview, questionnaire and document analysis - the middle two ones have been used predominantly in the study.

To acquire the primary data and verify the research output, semi-structured and structured interviews have been conducted. The former interview, as a basic research technique for collecting data, was supplemented by a questionnaire survey containing closed, semi-open and open questions. A combination of the above methods was employed to minimize the risk of misunderstanding the survey questions and allow greater flexibility in responding. Thus, more information was gained and the possibility of unintentional omission of relevant research factors eliminated.

Appropriate statistical methods have been employed with respect to mostly qualitative and categorical research data. The following bullets can be understood as a procedure for obtaining probabilities in a commercial risk model management. It is a definition of steps that include understanding and managing data, finding relationships and dependencies, and obtaining probabilities presented in the results. The application of mathematical statistics and probability theory to obtain probabilities is described in this and the following chapter. The study applies the methods of:

- descriptive statistics - for the purpose of organizing and describing data, using numerical summaries, graphs and other resources; descriptive statistics also fulfilling an exploration function

- statistical dependency analysis - in order to determine whether there is a relationship between the values of individual variables monitored, when due to the nature of the primary data, the Kruskal-Wallis test, $\chi^{2}$ test and Pearson's and Cramer's contingency coefficients are applied 
- cluster analysis - to place objects in groups so that those in a particular group are as similar as possible or more similar to each other than two objects from different groups; cluster analysis being also a useful tool to identify new data configurations

- mathematical statistics - based on probability theory, its purpose is to analyse the data obtained by examining the statistical set and to subsequently extend the conclusions to the whole basic set, applying principles of the so-called statistical induction

- probability statistics - i.e. the very basis for constructing a commercial risk model for export to China

Calculations, charts and tables were processed using Excel spreadsheets and XLStatistics and Matlab software.

\section{RESULTS AND DISCUSSION}

Content analysis has yielded findings that combine, supplement and reinforce the conclusions of the studies overviewed in the second subsection of this paper.

The research has confirmed that unpreparedness for specific risks that may arise in China can have unfortunate economic consequences, this corresponding to the outcomes of a broader study by Hudakova et al. (2018).

A number of publications mentioned above (Zhang et al., 2018; Zheng, 2011) show an effort to maintain online communication that reduces the need for physical presence in a given location, thus facilitating business dealings. The present study concludes (Wang, 2016) that despite technologies making effective communication and trading smoother, Chinese business habits and pragmatism make it impossible to conduct trade negotiations in virtual environment only. The presence of a sales representative remains important for establishing contacts, selling, settling disputes and controlling quality.

Cultural differences are crucial in business dealings with Chinese counterparts, the respondents' practical experiences having extended the research results beyond expectations.

Particular manifestations of Chinese habitual behaviours described above become apparent over the course of business negotiations, which can be described as follows. The Chinese side, usually outnumbering their counterparts, is fully equipped for business meetings, including with the technicalities of the deal. Employing sophisticated techniques, it pushes the counterparty to make concessions, accept a minimum price and share maximum information. Chinese negotiators' own decisions, on the other hand, are to be first discussed by the team, often being delayed - especially when they concern issues more complex than expected. Using time pressure coercively and showing ostensible indifference, they try to maximize their benefits. The deal having been finally struck, even then it could happen that in the case of any change in the initial conditions (such as that in input prices in favour of the counterparty), the Chinese team would push for contract amendments to make the agreement equally beneficial for them. However, the Chinese approach is based on pragmatism rather than principle, the perspective of long-term cooperation shaping the way the results of such negotiations are handled and interpreted. 
In China, there is widespread distrust of the unknown, including strangers. Social connections and relationships (kuan-si) are necessary not only to settle disputes between partners, but also to open up business opportunities and acquire information and referrals. If a company does not have a network of such links, it can hire intermediaries who will introduce it to the right people, referencing the reliability of the potential partner. The intermediaries can be, for example, companies that are already established in the Chinese market, embassy representatives or independent sales reps. Without good connections, firms entering the market face difficulties in establishing business partnerships and dealing with administration and red tape in particular. With the help of connections, information on the solvency and soundness of the partner can be extracted, relevant financial statements usually not providing it.

Content analysis has also confirmed the role of the diplomatic representation of exporters to China, which should not be only formal or purely administrative. During the research, some of the exporting firms' executives were addressed, underscoring the need for greater support from the Czech embassy in China; they admit that they receive more assistance from the diplomatic corps of Slovakia, whose business ownership relations are intertwined with those of the Czech Republic. These findings can affect the value of the variables and be dealt with in further research. The conclusions of the study by Dobes et al. (2017) can thus be supplemented by the issue of encouraging exporters to create more favourable business conditions.

The power of diplomacy and political culture of countries trading with China intermingles with the effects of local concepts of "preserving face", networking connections and work units, based on collective decision-making. If, for example, a representative of the Czech Republic expresses a private opinion in public, it may be perceived by the Chinese side as a collective view; it may have serious consequences, such as blockage of goods in a customs warehouse or termination of contracts. Media coverage of the Chinese issues often carries negative political connotations lacking wider historical and cultural contexts. This biased perspective hinders a constructive bilateral trade dialogue.

It is clear from the above that in order to build good business relationships, it is necessary to understand the partner's cultural background. In the case of China, an overseas trade delegation negotiates with the team whose success is a matter of honour and keeping face. The success of negotiations lies not only in expertise, intelligence, patience and connections on the ground, but also in understanding procedures, body language and social idioms. It is advisable to communicate through an experienced interpreter and engage a sales representative or other person who is familiar with the local market. Otherwise, the foreign company may get exposed to negative impacts of a range of risks, including commercial ones. Apart from these general recommendations, there is a detailed negotiation protocol which facilitates communication with Chinese business partners. However, it is not necessary to fully comply with the protocol since it could paradoxically undermine the bargaining position.

The present research confirms the importance of understanding Chinese cultural identity as manifested in the principles which are reflected in the course of trade dealings and in the ensuing commercial risks. The influence of the most important concept of kuan-si (the network of acquaintances) on economic performance, society and morals has been examined in a growing body of the above-mentioned literature. Both current and previous studies (Gao et al., 2012; Ip, 
2009; Tsai et al., 2011; Wang, 2016; Yeh \& Xu, 2010), however, suggest that Chinese cultural values and business practices overall appear incomprehensible to Westerners. Despite abandoning some of the customs that assumed dogmatic forms in the Maoist era, the Chinese still proudly proclaim their Confucian heritage and traditions.

In terms of Confucianism, this research has empirically corroborated the conclusions of numerous studies that its influence remains permanent and undeniable. Confucian principles are applied to the corporate management (Miles \& Goo, 2013; Weber, 2009), and intermingle with HR management (Bettignies et al., 2011). Confucian behavioural norms are the moral anchor for employees, impacting positively on the overall opening to the West (Han \& Altman, 2010). A Confucian political order is rooted in the philosophy of humanity as a principle of maintaining harmony between different national traditions in a globalized world, allowing for a common international "speech" (Cheng, 2011), thus seeking to contribute positively to the entire world. The teachings of Confucius are still likely to shape human behaviour in China much more than modern individualism and collectivism (Hsieh, 2011).

The mentality of Chinese society is obviously reflected in the current state of mutual trade between the Czech Republic and the People's Republic of China. Practical experiences and research outcomes over the last decade suggest that ignoring the cultural heritage of the Chinese nation may complicate the establishment of business relations, thus increasing commercial risk and discouraging further cooperation. Any attempt to penetrate the local market without taking these aspects of Chinese culture into consideration would be doomed to failure.

As far as the variables included in the commercial risk model are concerned, this research has yielded the following results:

Given that only a statistically small sample was available, the hypothesis test for the parameter $p$ of a binomial distribution was not primarily used to confirm the null hypothesis from the observed $p_{0}$ ratio, but to find the maximum and minimum probabilities when the null hypothesis still applies (see section 3). This allows for the derivation of the occurrence probability interval for every risk, excluding that of insolvency, since this particular risk was not shown to occur with the available data. Assuming that China is too geographically distant for Czech firms to successfully do business on the local market, the upper limits of probabilities enter the probability model. The particular probability intervals are as follows:

- Minimum probability of the risk of withdrawal from a contract is 0.1353 (i.e. $13.53 \%$ ), maximum value reaching 0.5057 (50.57\%).

- Minimum probability of the risk of a parametric change in a contract is $0.7342(73.42 \%)$, maximum amounting to $0.9840(98.40 \%)$.

- Minimum probability of the risk of non-delivery is $0.1353(13.53 \%)$, the maximum value being 0.5057 (50.57\%).

- Minimum probability of the risk of default of the business partner is $0.0890(8.9 \%)$, maximum reaching $0.4322(43.22 \%)$.

On-site experience and an improved understanding of the cultural background can help to reduce the probability of risk occurrence towards the minimum calculated level. Given the charac- 
teristics of the territory, it is appropriate to expect the maximum initial level of risk probability. Each partial commercial risk may also trigger another risk, namely that of additional costs. Thus, in terms of probability theory a conditional probability emerges, with a certain phenomenon (additional costs) being conditional upon the occurrence of another phenomenon (particular commercial risk). The phenomenal field is narrowed by the prerequisite that the so-called B-phenomenon arises, allowing for the occurrence of an A-phenomenon. Then, it holds that

$P(A \mid B)=\frac{P(A \cap B)}{P(B)}$

(Cruz et al., 2015; Freund et al., 2010).

Again, the test of the $p$ parameter for the binomial distribution was performed to derive the probability of additional costs incurred by partial commercial risk. Given the nature of the phenomenon being investigated, only the maximum probability was determined. The risk of incurring additional costs is thus driven by the hypergeometric probability distribution, from which likelihoods of additional costs were derived for cases in which partial commercial risks arise. Table 2 gives an overview of conditional and unconditional probability in the commercial risk assessment model.

Tab. 2 - Conditional and unconditional probabilities in the commercial risk assessment model. Source: own research

\begin{tabular}{|l|l|l|}
\hline \multirow{2}{*}{\multicolumn{1}{|c|}{ Partial risk }} & \multicolumn{2}{c|}{ Probability of } \\
\cline { 2 - 3 } & risk occurring $P\left(S_{i}\right)$ & incurring additional costs $P\left(H_{i k} / S_{i}\right)$ \\
\hline Withdrawal from contract & 0.5057 & 0.8910 \\
\hline Contract parameter change & 0.9840 & 0.6450 \\
\hline Non-acceptance of order & 0.5057 & 1.0000 \\
\hline Customer default & 0.4322 & 0.9130 \\
\hline
\end{tabular}

\section{CONCLUSION}

The present paper has confirmed and extended the knowledge gained from secondary sources and previous research. Generally, understanding cultural differences is a prerequisite for effective international trade, despite a significant part of this being conducted online. Specifically, in terms of export to China, an insufficient adaptation to the local environment has profound consequences. The personal on-site presence of a sales representative is still of prime importance for establishing business contacts, promoting the sales of products, controlling quality as well as resolving disagreements. In exporting to China, online trade management cannot be relied on to deliver added cost advantages.

Business negotiations are usually rather tough, with the Chinese side trying to acquire the most information and negotiate the lowest price with the greatest concessions to them possible. Major decisions are taken collectively and often deliberately delayed. Through time pressure and a feigned lack of interest, they strive to maximize the benefits to them. If this fails, it is a common 
practice to initiate further negotiations in order to conclude a more advantageous contract. All the potential challenges and pitfalls having been overcome, a working business relationship with a Chinese partner has great potential to sustain cooperation in the long run.

For all of these reasons, Chinese cultural traits deserve practical consideration. Through kuansi (personal connections), business relations can be developed, conflicts solved, bureaucracy circumvented, and information on trading partners obtained. This concept of acquaintanceship mingles with those of the working unit (tan-wej), keeping face (mien-c') and gentle courtesy (li-ti). It should be also remembered that the behaviour of an individual can be perceived by the Chinese as an expression of the whole group. Inappropriate behaviour exhibited or an unintentional offence committed make it more difficult to negotiate. These factors fundamentally affect the occurrence of commercial risk and the ways of facing it. They also indicate the value of the assessment model coefficients.

All combinations of partial commercial risks and their probabilities can be theoretically incorporated into the final model. In practice, however, some of these combinations are unlikely or impossible, since the following risk occurrences are mutually exclusive: the risk of withdrawing from a contract vs. the risk of unjustified non-acceptance of the order, the risk of withdrawing from a contract vs. the risk of a customer default, the risk of unjustified non-acceptance of the order vs. the risk of a customer default.

Overall, there are only three possible pairs of risks out of 16 combinations which may occur simultaneously within one business case. All three pairs contain the risk of changing the parameters of the contract, which is combined with the risk of: withdrawing from the contract, not accepting the order unreasonably, customer defaulting.

Based on the above assumptions and findings, an assessment model of the commercial risk of exporting to Chinese markets will be developed in future studies.

The commercial risk assessment model will imply relative additional risk costs incurred in a particular phase of a business process (offer, enquiry, negotiation and contract), with the model output reflecting the expected theoretical mean value of costs or losses caused by commercial risk occurrence. These results are very useful for financial management and sales departments of corporates.

The present research paper contains the experience of exporters facing daily business risks. The commercial risk model will be particularly useful for Czech exporters, while for sellers from other countries, the model coefficients would be somewhat different, although the methodology, nonetheless, should remain the same. It is also worthy of attention that the lessons learned from this content analysis of questionnaires are applicable to both exporters and importers operating in international markets.

Follow-up studies will consider broader issues concerning the commercial risk assessment model and its practical use. Suggestions regarding how to minimize the impacts of commercial risks associated with cultural differences will be summarized. The research can be further extended into other domains, such as international business operations, corporate finance, banking and insurance, marketing, law, or even philosophy. (In terms of banking, for example, creditworthiness, liquidity or non-payment risk would be interesting to explore. Chinese national and 
regional legislation, on the other hand, can be rather complex to be fully exploited for business uses.) Partial manifestations of commercial risk can be analysed separately as well, with obvious potential reference overlaps between various research subject areas.

The sheer scope of the research and this different approach compared to more narrowly-focused studies can themselves be seen as limiting factors. In collecting data, it was necessary to explore several disciplines and to seek suitable ways of presenting the results. The outcomes could be verified by analogous studies undertaken within a stronger export-oriented (e.g. German) economy. In addition, the shared experiences of exporters from other backgrounds might be enriching. The aim of this research is also to support the competitiveness of Czech businesses who want to access the market in China, with initiating export into this massive market proving to be a simple test of competitiveness for companies of other nations as well.

\section{References}

1. Alma, B. (2017). Strategic Decision Making Of Micro-Lenders: An Innovative Business Model For Risk Management. The European Proceedings of Social \& Behavioural Sciences EpSBS, 308-321. https://doi.org/10.15405/epsbs.2017.12.02.26

2. Amadeus database. (2018). Retrieved from https://amadeus.bvdinfo.com/version-2018125/ home.serv?product=AmadeusNeo.

3. Amat, O., Manini, R., \& Antón Renart, M. (2017). Credit concession through credit scoring: Analysis and application proposal. Intangible Capital, 13 (1), 51-70. https://doi. org/10.3926/ic. 903

4. Anděl, J. (2007). Statistické metody. Praha: Matfyzpress.

5. Bedford, O. (2011). Guanxi-Building in the Workplace: A Dynamic Process Model of Working and Backdoor Guanxi. Journal of Business Ethics, 104 (1), 149-158. https://doi. org/10.1007/s10551-011-0895-9

6. Belas, J., Cipovova, E., Novak, P. \& Polach, J. (2012). Impacts of the Foundation Internal Ratings Based Approach Usage on Financial Performance of Commercial Bank. E+M Ekonomie a Management, Vol. 15, Issue 3, 142-154.

7. Bott, J., \& Milkau, U. (2018). Risk Culture and the Role Model of the Honorable Merchant. Journal of Risk and Financial Management, 11 (3). https://doi.org/10.3390/jrfm11030040

8. Brillinger, A.-S. (2018). Mapping business model risk factors. International Journal of Innovation Management, 22 (05). https://doi.org/10.1142/S1363919618400054

9. Cabré, M. M., Gallagher, K. P., \& Li, Z. (2018). Renewable Energy: The Trillion Dollar Opportunity for Chinese Overseas Investment. China \& World Economy, 26 (6), 27-49. https://doi.org/10.1111/cwe.12260

10. Černohlávková, E. (2007). Finanční strategie v męinárodním podnikání. Praha: ASPI.

11. Chen, Y., Chen, D., Wang, W., \& Zheng, D. (2018). Political uncertainty and firms' information environment: Evidence from China. Journal of Accounting and Public Policy, 37 (1), 39-64. https://doi.org/10.1016/j.jaccpubpol.2018.01.005 
12. Cheng, C. (2011). Confucian Global Leadership in Chinese Tradition. Journal of Management Development, 30 (7/8), 647-662. https://doi.org/10.1108/02621711111150173

13. Cruz, M. G., Peters, G. W., \& Shevchenko, P. V. (2015). Fundamental aspects of operational risk and insurance analytics: a bandbook of operational risk. New Jersey: Wiley.

14. CSO. (2017). External trade of the Czech Republic - annual data - 2016. Retrieved August 10, 2018, from https://www.czso.cz/csu/czso/external-trade-of-the-czech-republic-annualdata

15. CSO. (2018). External trade of the Czech Republic - annual data - 2017. Retrieved September 10, 2019, from https://www.czso.cz/csu/czso/external-trade-of-the-czechrepublic-annual-data-2016

16. de Bettignies, H.-C., Ip, P. K., Bai, X., Habisch, A., \& Lenssen, G. (2011). Practical Wisdom for Management from the Chinese Classical Traditions. Journal of Management Development, 30 (7/8), 623-628. https://doi.org/10.1108/02621711111150155

17. Dobes, K., Kot, S., Kramolis, J., \& Sopkova, G. (2017). The Perception of Governmental Support in the Context of Competitiveness of SMEs in the Czech Republic. Journal of Competitiveness, 9 (3), 34-50. https://doi.org/10.7441/joc.2017.03.03

18. Dostál, P., Rais, K., \& Sojka, Z. (2005). Pokročilé metody manažerskébo roz̧hodování (1. vyd.). Praha: Grada.

19. Fan, Y. (2002). Ganxi's consequences: Personal gains at social cost. Journall of Business Ethics, 38 (4), 371-380. https://doi.org/10.1023/A:1016021706308

20. Fotr, J., \& Hnilica, J. (2014). Aplikovaná analyza rizika ve finančním managementu a investičním roz̧odování. Praha: Grada.

21. Freund, R. J., Wilson, W. J., \& Mohr, D. L. (2010). Statistical methods (3rd ed.). Boston: Elsevier.

22. Gao, H., Knight, J. G., \& Ballantyne, D. (2012). Guanxi as a gateway in Chinese-Western business relationships. Journal of Business \& Industrial Marketing, 27 (6), 456-467. https://doi. org $/ 10.1108 / 08858621211251460$

23. Grath, A. (2008). The handbook of international trade and finance. London: Kogan Page.

24. Halleck-Vega, S., Mandel, A., \& Millock, K. (2018). Accelerating diffusion of climatefriendly technologies: A network perspective. Ecological Economics, 152 (1), 235-245. https:// doi.org/10.1016/j.ecolecon.2018.05.007

25. Han, Y., \& Altman, Y. (2010). Confucian Moral Roots of Citizenship Behaviour in China. Asia-Pacific Journal of Business Administration, 2 (1), 35-52. https://doi.org/10.1108/175743210 11028963

26. Hendl, J. (2015). Prehled statistických metod: analýza a metaanalýza dat. Praha: Portál.

27. Hofstede, G. (1997). Cultures and organizations ([Rev. ed.]). New York: McGraw-Hill.

28. Hsieh, Y. J. (2011). Cross-cultural Communication. Advances in International Marketing, 21, 283-307. https://doi.org/10.1108/S1474-7979(2011)0000021015 
29. Hudakova, M., Masar, M., Luskova, M., \& Patak, M. R. (2018). The Dependence of Perceived Business Risks on the Size of SMEs. Journal of Competitiveness, 10 (4), 54-69. https://doi.org/https://doi.org/10.7441/joc.2018.04.04

30. Ip, P. K. (2009). Is Confucianism Good for Business Ethics in China? Journal of Business Ethics, 88 (3), 463-476. https://doi.org/10.1007/s10551-009-0120-2

31. Jia, L., You, S., \& Du, Y. (2012). Chinese Context and Theoretical Contributions to Management and Organization Research. Management and Organization Review, 8 (1), 173-209. https://doi.org/10.1111/j.1740-8784.2011.00282.x

32. Jorge, R. R., Facó, J. F. B., \& Acácio, A. A. (2017). A transmissão de risco de crédito em cadeia de suprimentos. Revista Gestão \& Tecnologia, 17 (2), 134-159. https://doi. org/10.20397/2177-6652/2017.v17i2.1105

33. Justice.cz. (2016). Retrieved December 10, 2016, from http://portal.justice.cz/Justice2/ Uvod/uvod.aspx

34. Kliestik, T., Misankova, M., Valaskova, K., \& Svabova, L. (2018). Bankruptcy prevention: new effort to reflect on legal and social changes. Science and Engineering Ethics, 24(2), 791-803. https://doi.org/10.1007/s11948-017-9912-4

35. Korecký, M., \& Trkovský, V. (2011). Management riziik projektů (1. vyd.). Praha: Grada.

36. Li, L. (2018). China's manufacturing locus in 2025: With a comparison of "Made-in-China 2025" and "Industry 4.0." Technological Forecasting and Social Change, 135(1), 66-74. https://doi. org/10.1016/j.techfore.2017.05.028

37. Luo, D., Chen, K. C., \& Wu, L. (2017). Political uncertainty and firm risk in China. Review of Development Finance, 7 (2), 85-94. https://doi.org/10.1016/j.rdf.2017.06.001

38. Machková, H. (2010). Mezinárodni obchodni operace (5., aktual). Praha: Grada.

39. Mareš, D., \& Petrů, N. (2018). Stabilization factors of family enterprises in the context of macroeconomic performance. European Research Studies Journal, 21 (1), 206-220.

40. Miles, L., \& Goo, S. H. (2013). Corporate Governance in Asian Countries. Business and Society Review, 118 (1), 23-45. https://doi.org/10.1111/basr.12001

41. Palát, M. (2014). The causes of migration initiation and reflections on related theories. In 17th International Colloquium on Regional Science. Brno: Masaryk University.

42. Petrů, N., Tomášková, A. \& Krošláková, M. (2019). Diversification of Export Territories of Family Businesses as a Tool of their Futher Development. Problems and Perspectives in Management, 17 (3), 306-322. doi:10.21511/ppm.17(3).2019.25

43. Polák, J. (2016). Possibilities in Verification of Chinese Business Partner Using the Available IT. In Informatization of Economic and Management Processes. Brno: B.I.B.S., a.s.

44. Priority country for export. (2012). In BusinessInfo.cz. Retrieved from http://www. businessinfo.cz/cs/clanky/nove-prioritni-zeme-pro-export-3812.html

45. Seligman, S. D. (2007). Chinese Business Etiquette: A Guide to Protocols, Social Behavior and Culture in China (1st ed.). Praha: BB/art. 
46. Skoglund, J., \& Chen, W. (2017). Rating momentum in the macroeconomic stress testing and scenario analysis of credit risk. The Journal of Risk. Model Validation, 11 (1), 21-47. https:// doi.org/10.21314/JRMV.2017.167

47. Song, M., Wang, S., \& Sun, J. (2018). Environmental regulations, staff quality, green technology, R\&amp;D efficiency, and profit in manufacturing. Technological Forecasting and Social Change, 133 (C), 1-14. https://doi.org/10.1016/j.techfore.2018.04.020

48. Špaček, M. (2014). Pravděpodobnostni prístupy k analýze riq̨ik investičnich projektů a jejich využití v praxi. Plzeň: Nava.

49. Statistics Explained: International trade in goods. (2018). Retrieved June 8, 2018, from http://ec.europa.eu/eurostat/statistics-explained/index.php?title=International_trade_in_ goods/cs

50. Tam, S. (2016). From understanding business guanxi to practising it: a golden rule for MNCs in China. Journal of Chinese Human Resources Management, 7 (1), 39-44. https:/doi. org/10.1108/JCHRM-06-2016-0008

51. Tsai, T., Young, M. N., \& Cheng, B. (2011). Confucian Business Practices and Firm Competitiveness. Frontiers of Business Research in China, 5 (3), 317-343. https://doi. org/10.1007/s11782-011-0133-4

52. Valaskova, K., Kliestik, T., \& Kovacova, M. (2018). Management of financial risks in Slovak entrerprises using regression analysis. Oeconomia Copernicana, 9 (1), 105-121. https:// doi.org/10.24136/oc.2018.006

53. Wang, H. (2016). A Study of Influence of Cultural Differences on International Trade and the Development Countermeasures. In 5th International Conference on Education and Education Management. 243-246. Sydney: Fuzhou Univ Int Studies \& Trade, Dept Econ \& Trade, Fuzhou.

54. Weber, J. (2009). Using Exemplary Business Practices to Identify Buddhist and Confucian Ethical Value Systems 1. Business and Society Review, 114 (4), 511-540. https://doi.org/10.1111/ j.1467-8594.2009.00352.x

55. Xu, G., Wu, Y., Minshall, T., \& Zhou, Y. (2018). Exploring innovation ecosystems across science, technology, and business: A case of 3D printing in China. Technological Forecasting and Social Change, 208-221. https://doi.org/10.1016/j.techfore.2017.06.030

56. Yao, M., Di, H., Zheng, X., \& Xu, X. (2018). Impact of payment technology innovations on the traditional financial industry: A focus on China. Technological Forecasting and Social Change, 199-207. https://doi.org/10.1016/j.techfore.2017.12.023

57. Yeh, Q.-J., \& Xu, X. (2010). The Effect of Confucian Work Ethics on Learning About Science and Technology Knowledge and Morality. Journal of Business Ethics, 95(1), 111-128. https://doi.org/10.1007/s10551-009-0352-1

58. Zhang, D., Zheng, W., \& Ning, L. (2018). Does innovation facilitate firm survival? Evidence from Chinese high-tech firms. Economic Modelling, 458-468. https://doi. org/10.1016/j.econmod.2018.07.030

59. Zheng, L. (2011). Building and Analysis of Risk Control Models for Green Credit Business by Commercial Banks in China. Lancaster: Destech Publications, Inc. 
60. Zhuang, L., Ritchie, R., \& Zhang, Q. (1998). Managing business risks in China. Long Range Planning, 31 (4), 606-614. https://doi.org/10.1016/S0024-6301(98)80053-8

\section{Contact information}

Ing. Josef Polak, Ph.D.

The College of Regional Development and Banking Institute - AMBIS, a.s.

Department of Economics and Management

Czech Republic

E-mail:josefpolak@centrum.cz,josef.polak@ambis.cz.

ORCID: 0000-0002-7305-3379 